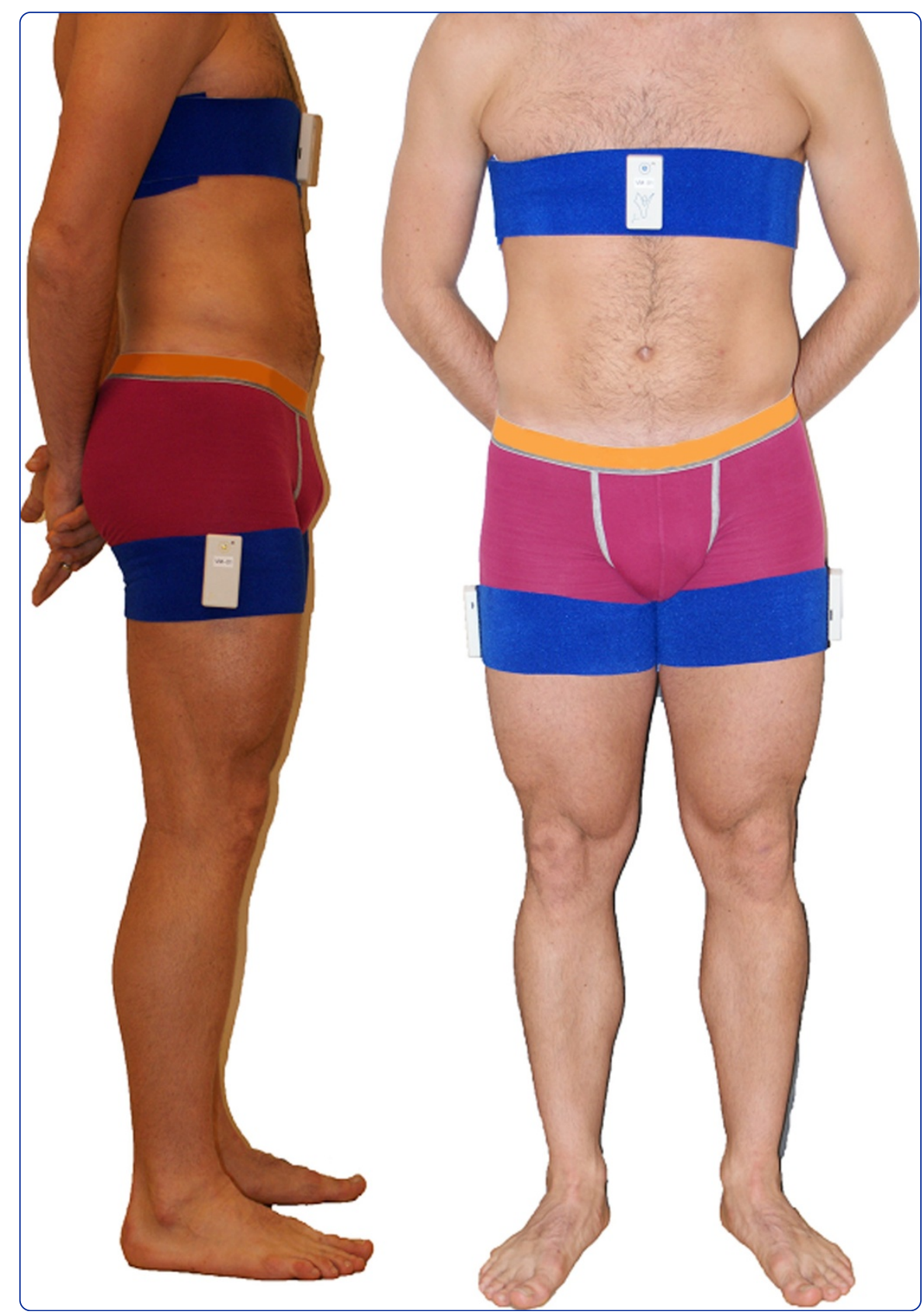

\title{
Inactive and sedentary lifestyles amongst ambulatory adolescents and young adults with cerebral palsy
}

Nooijen et al. 


\title{
Inactive and sedentary lifestyles amongst ambulatory adolescents and young adults with cerebral palsy
}

\author{
Carla FJ Nooijen*, Jorrit Slaman, Henk J Stam, Marij E Roebroeck, Rita J van den Berg-Emons and Learn2Move \\ Research Group
}

\begin{abstract}
Background: To assess physical behaviour, including physical activity and sedentary behaviour, of ambulatory adolescents and young adults with cerebral palsy (CP). We compared participant physical behaviour to that of able-bodied persons and assessed differences related to Gross Motor Functioning Classification System (GMFCS) level and CP distribution (unilateral/bilateral).
\end{abstract}

Methods: In 48 ambulatory persons aged 16 to 24 years with spastic CP and in 32 able-bodied controls, physical behaviour was objectively determined with an accelerometer-based activity monitor. Total duration, intensity and type of physical activity were assessed and sedentary time was determined (lying and sitting). Furthermore, distribution of walking bouts and sitting bouts was specified.

Results: Adolescents and young adults with CP spent $8.6 \%$ of 24 hours physically active and $79.5 \%$ sedentary, corresponding with respectively 123 minutes and 1147 minutes per 24 hours. Compared to able-bodied controls, persons with CP participated 48 minutes less in physical activities $(p<0.01)$ and spent 80 minutes more sedentary per 24 hours $(p<0.01)$. Physical behaviour was not different between persons with GMFCS level I and II and only number of short sitting bouts were significantly more prevalent in persons with bilateral CP compared to unilateral $\mathrm{CP}(\mathrm{p}<0.05)$.

Conclusions: Ambulatory adolescents and young adults with CP are less physically active and spend more time sedentary compared to able-bodied persons, suggesting that this group may be at increased risk for health problems related to less favourable physical behaviour.

Trial registration: Nederlands trial register: NTR1785

Keywords: Physical behaviour, Cerebral palsy, Sedentary time, Physical activity, Accelerometer

\section{Background}

Physical activity has been defined as "any bodily movement that results in energy expenditure" [1]. Physical activity contributes to the primary and secondary prevention of several chronic diseases, including cardiovascular disease, cancer, diabetes mellitus, hypertension and obesity, and is associated with a reduced risk of premature death in the general population [2]. Sedentary behaviour, defined as a distinct class of activities that require low levels of

\footnotetext{
* Correspondence: c.nooijen@erasmusmc.nl

Department of Rehabilitation Medicine, Research lines MoveFit \& Transition and Lifespan Research, Erasmus MC, University Medical Centre, P.O. Box 2040, 3000 CA Rotterdam, The Netherlands
}

\section{Biomed Central}

energy expenditure and involve sitting and lying [3], also negatively impacts metabolism and cardiovascular health [4]. Physical activity and sedentary behaviour are distinct aspects of physical behaviour [5]. Independent of physical activity, a person with a large amount of sedentary time may still be at risk of poor health outcomes [4]. Consequently, besides meeting physical activity guidelines it is also recommended to limit the amount of sedentary time [4].

Persons with cerebral palsy $(\mathrm{CP})$ experience problems with movement and posture, including difficulty with balance and walking, gross and fine motor control, and muscle spasticity. Therefore, they are at risk of reduced 
physical activity and increased sedentary behaviour [6]. Previously, it has been indicated that children and adults with $\mathrm{CP}$ participate substantially less in physical activities compared to reference populations, and less than recommended by guidelines [7-9]. With regard to sedentary behaviour, children aged 5 to 17 years with $\mathrm{CP}$ fail to achieve recommended activity levels [7]. To our knowledge, sedentary behaviour has not been studied previously in persons with $\mathrm{CP}$ after childhood.

Transition to adulthood is thought to be an important time for interventions that promote physical activity and limit sedentary time because at this age many changes in life may influence the adult lifestyle $[10,11]$. However, to our knowledge, physical behaviour for 16 to 24 year-olds has not yet been studied in persons with CP. Knowledge of physical behaviour at this age can help optimise recommendations and treatments to increase physical activity and limit sedentary behaviour in persons with $\mathrm{CP}$ across the lifespan. Furthermore, by comparing physical behaviour of subgroups based on $\mathrm{CP}$ characteristics, recommendations and treatments can be further optimised and tailored for disorder severity.

Therefore, the aim of the current study was to assess physical behaviour of ambulatory adolescents and young adults, aged 16 to 24 years, with spastic CP. Physical behaviour variables included objectively measured physical activity and objectively measured sedentary behaviour. Total duration, intensity and types of physical activities (walking, running, cycling, and non-cyclic movement) were assessed, and distribution of walking bouts was described. Total sedentary time was determined (sitting and lying) and specified with regard to total duration of sitting and distribution of sitting bouts. Furthermore, self-reported physical activity was assessed. Objective data were compared with data of able-bodied controls, and differences within the $\mathrm{CP}$ group related to Gross Motor Functioning Classification System (GMFCS) and distribution of CP (unilateral/bilateral) were explored.

\section{Methods}

This study is part of the longitudinal, multi-centre, randomised controlled trial Learn2Move 16-24, which evaluates an intervention to promote daily physical activity and sports participation, reduce sedentary behaviour, and improve physical fitness amongst adolescents and young adults with spastic CP [12]. In the current study, baseline data from the longitudinal study were used.

\section{Participants}

Adolescents and young adults with spastic unilateral or bilateral CP, aged 16 to 24 years, were recruited from six rehabilitation centres and rehabilitation departments at university hospitals in west-central Netherlands, and by the Association of Physically Disabled Persons and their Parents.

Exclusion criteria were: 1) disabilities other than CP that affect physical activity or physical fitness; 2) contraindications to (maximal) exercise; 3) severe cognitive disorders or insufficient comprehension of Dutch; 4) partly dependent or fully dependent on a manual wheelchair; 5) physical activity level higher than $15.6 \%$ of 24 hours (mean physical activity level +2 standard deviations (SD) of an adult CP population) [9]. No one was excluded by this latter criterion.

All participants provided written informed consent. The study was approved by the Medical Ethics Committee of the Erasmus Medical Centre. Local approval was granted by all participating centres.

\section{Physical behaviour}

To objectively measure physical behaviour, we used the ambulatory monitoring system VitaMove (2M Engineering, Veldhoven, The Netherlands), with body-fixed accelerometers (Freescale MMA7260Q, Denver, USA) (Figure 1). This activity monitor has demonstrated validity to quantify mobility-related activities and postures and to detect intergroup differences in physical behaviour $[13,14]$. The system consists of three recorders that are wirelessly connected and synchronised every ten seconds. One recorder was attached to each thigh and a third recorder was attached to the sternum. The recorders were worn on the body using elastic belts. The measurements were started at participants' homes and activity monitors were worn continuously on consecutive weekdays, except during swimming, bathing and sleeping. Participants kept activity diaries that allowed for correction for periods of non-wearing time of the activity monitor. The intended duration of measurement was 72 hours with a minimum duration of 24 hours. This minimum duration was previously established as adequate for determining activities and postures [15]. To avoid measurement bias, we instructed participants to continue their ordinary daily life and the principles of the activity monitor were only explained after study completion.

Accelerometer signals for each recorder were sampled and stored digitally on a micro Secure Digital memory card. Measurements were uploaded to a computer for kinematic analysis using VitaScore Software (VitaScore BV, Gemert, The Netherlands). The duration, rate, and moment of occurrence of physical activity, sedentary behaviour, and transitions between postures were automatically and separately detected with a 1-second resolution. Furthermore, motility was determined, which provides information on the variability of the acceleration signal and is related to the intensity of body-segment movements. A detailed description of the configuration and analysis has been described elsewhere [13]. 


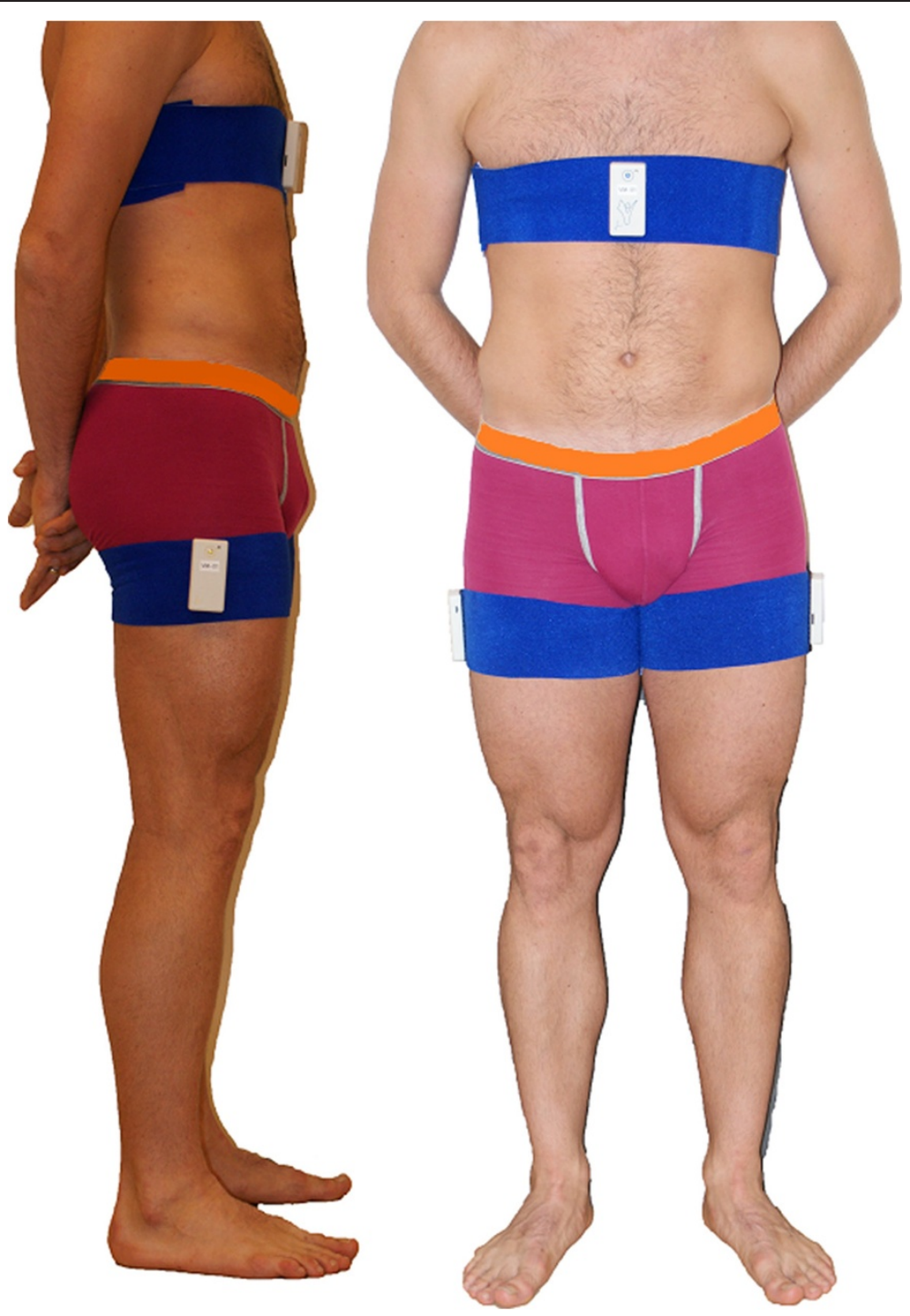

Figure 1 VitaMove activity monitor.

The following data were obtained:

1. Total duration of physical activities, including walking, running, cycling, and non-cyclic movement and separate duration of each of these activities. All physical activity measures were expressed as a percentage of a 24-hour period.

2. Total duration of sedentary behaviour, including sitting and lying, and separate duration of sitting and standing, all expressed as a percentage of a 24-hour period.

3. Mean motility of the total of physical activities and mean motility of walking, expressed as gravitational force $(\mathrm{g})$.

4. Distribution of continuous walking and sitting bouts with pre-defined durations: 0-10 sec; 10-60 sec; 1-10 min; $10-30 \mathrm{~min}$; or > $30 \mathrm{~min}$.
For reference, we used activity monitor data of 32 able-bodied persons aged 14 to 29 years available from previous studies at our department (mean age 22 years $(\mathrm{SD}=5), 14$ males). All able-bodied persons wore the activity monitor for two consecutive weekdays. Measurements were performed with a non-wireless version of the activity monitor and analysed with a previous software version. However, the underlying technique of the activity monitor is the same as that of the monitors worn by the participants with $\mathrm{CP}$, and the algorithms of data analysis comparable between software versions. Data for participants with CP were expressed as a percentage of reference data.

Self-reported physical activity levels were measured with the Dutch version of the Physical Activity Scale for Individuals with Physical Disabilities (PASIPD) [16], a 
Table 1 Characteristics, physical activity, sedentary time and self-reported physical activity

\begin{tabular}{|c|c|c|c|c|c|c|c|c|c|c|}
\hline \multirow[b]{2}{*}{ Characteristics } & \multirow[t]{2}{*}{$\mathrm{CP}$} & \multirow[t]{2}{*}{ Able-bodied $^{4}$} & \multirow[b]{2}{*}{ Mean dif. ${ }^{5}$} & \multirow[b]{2}{*}{$p^{6}$} & \multirow[b]{2}{*}{$95 \% \mathrm{Cl}$} & \multicolumn{3}{|c|}{ GMFCS level $^{7}$} & \multicolumn{2}{|c|}{ CP distribution ${ }^{8}$} \\
\hline & & & & & & I & $\|$ & III & Unilateral & Bilateral \\
\hline Number of participants & 48 & 32 & & & & 29 & 15 & 4 & 27 & 21 \\
\hline Age, mean (SD) & $20(3)$ & $22(5)$ & & 0.1 & & $19(2)$ & $21(3)$ & $19(2)$ & $19(2)$ & $21(3)$ \\
\hline $\begin{array}{l}\text { Gender, number of } \\
\text { males/females }\end{array}$ & $23 / 25$ & $18 / 14$ & & 0.5 & & $13 / 16$ & $8 / 7$ & $2 / 2$ & $11 / 16$ & $12 / 9$ \\
\hline \multicolumn{11}{|l|}{ Physical activity mean (SD) } \\
\hline \% Physical activities ${ }^{1}$ & $8.6(3.0)$ & $12.0(3.9)$ & -3.4 & $<0.01^{*}$ & $-5.2--2.1$ & $9.2(3.2)$ & $8.3(2.4)$ & $5.1(1.0)$ & $8.8(2.9)$ & $8.2(3.2)$ \\
\hline$\%$ Walking & $4.3(2.3)$ & $8.5(3.5)$ & -4.2 & $<0.01^{*}$ & $-5.6--3.0$ & $4.9(2.3)$ & $4.0(2.0)$ & $1.5(1.4)$ & $4.7(2.2)$ & $3.8(2.5)$ \\
\hline \% Running & $0(0.1)$ & $0.1(0.5)$ & -0.08 & 0.18 & $-0.3-0.1$ & $0(0.1)$ & $0(0)$ & $0.1(0.1)$ & $0(0.1)$ & $0(0.1)$ \\
\hline \% Cycling & $1.1(1.2)$ & $1.4(1.8)$ & -0.3 & 0.10 & $-1.2-0.1$ & $1.2(1.2)$ & $0.9(1.1)$ & $0.9(1.4)$ & $1.2(1.2)$ & $0.9(1.1)$ \\
\hline$\%$ Non-cyclic movement & $3.2(1.7)$ & $1.8(1.1)$ & 1.4 & $<0.01^{*}$ & $0.7-2.1$ & $3.2(1.7)$ & $3.4(1.9)$ & $2.6(1.7)$ & $2.9(1.6)$ & $3.5(1.9)$ \\
\hline Motility physical activities $(g)^{2}$ & $43.9(8.1)$ & & & & & $45.5(5.5)$ & $41.9(11.0)$ & $40.3(10.2)$ & $45.8(5.7)$ & $41.5(9.9)$ \\
\hline Motility walking $(g)^{2}$ & $52.6(8.9)$ & & & & & $52.9(6.9)$ & $52.1(9.5)$ & $52.3(16.3)$ & $53.8(7.5)$ & $50.9(9.9)$ \\
\hline $0-10$ sec walking bouts & $124.6(45.4)$ & & & & & $137.0(41.1)$ & $117.0(41.9)$ & $63.6(40.1)$ & $132.0(39.9)$ & $115.2(51.0)$ \\
\hline $10-60$ sec walking bouts & $88.8(48.3)$ & & & & & $100.8(50.1)$ & 79.5 (37.5) & $36.2(32.8)$ & $96.1(45.2)$ & $79.4(51.6)$ \\
\hline 1-10 min walking bouts & $7.1(6.0)$ & & & & & $7.7(5.8)$ & $7.7(6.3)$ & $0.8(1.5)$ & $7.5(4.9)$ & $6.6(7.2)$ \\
\hline 10-30 min walking bouts & $0.1(0.3)$ & & & & & $0.1(0.3)$ & $0.1(0.3)$ & 0 & $0.1(0.3)$ & $0.02(0.1)$ \\
\hline$>30$ min walking bouts & 0 & & & & & 0 & 0 & 0 & 0 & 0 \\
\hline \multicolumn{11}{|l|}{ Sedentary time mean (SD) } \\
\hline $\begin{array}{l}\text { \% Sedentary time } \\
{\text { (sitting + lying })^{3}}^{\text {S }}\end{array}$ & $79.5(7.1)$ & $74.0(7.5)$ & 5.5 & $<0.01^{*}$ & $1.6-8.3$ & $77.9(7.0)$ & $80.6(5.8)$ & $87.4(7.6)$ & $78.7(6.8)$ & $80.6(7.5)$ \\
\hline$\%$ Sitting & $36.8(8.1)$ & $36.7(7.0)$ & 0.1 & 0.79 & $-3.1-4.1$ & $36.6(7.6)$ & $35.7(8.8)$ & $42.3(8.0)$ & $36.9(8.6)$ & $36.7(7.5)$ \\
\hline 0-10 sec sitting bouts & $18.0(12.2)$ & & & & & $15.6(7.8)$ & $22.0(17.4)$ & $19.8(15.2)$ & $14.8(7.4)$ & $22.0(15.8)$ \\
\hline $10-60$ sec sitting bouts & $34.7(19.3)$ & & & & & $31.7(14.7)$ & $38.5(22.8)$ & $41.7(33.9)$ & $29.6(15.0)$ & $41.2(22.7)$ \\
\hline 1-10 min sitting bouts & $40.2(19.2)$ & & & & & $39.7(18.2)$ & $40.0(18.2)$ & 44.5 (33.6) & $38.1(18.3)$ & $42.9(20.4)$ \\
\hline $10-30$ min sitting bouts & $11.4(3.3)$ & & & & & $11.8(3.0)$ & $10.9(3.3)$ & $10.4(6.0)$ & $11.8(3.2)$ & $10.9(3.5)$ \\
\hline$>30$ min sitting bouts & $3.5(1.9)$ & & & & & $3.3(1.9)$ & $3.3(1.5)$ & $5.0(3.0)$ & $3.5(2.0)$ & $3.4(1.9)$ \\
\hline$\%$ Standing & $11.9(5.4)$ & $13.2(5.3)$ & -1.3 & 0.54 & $-3.2-1.7$ & $12.9(5.3)$ & $11.1(4.9)$ & $7.6(6.7)$ & $12.5(5.5)$ & $11.2(5.4)$ \\
\hline \multicolumn{11}{|l|}{ Self-reported physical activity } \\
\hline PASIPD (MET-hr/day), mean (SD) & $13.0(8.6)$ & & & & & $15.3(9.5)$ & $9.8(6.0)$ & $7.8(2.4)$ & $14.6(8.5)$ & $10.9(8.5)$ \\
\hline
\end{tabular}

${ }^{1}$ Physical activities is total duration of walking, running, cycling, and non-cyclic movement, as a $\%$ of 24 hours.

${ }^{2} \mathrm{~g}=$ gravitational forces ${ }^{*} 100$.

${ }^{3}$ Sedentary time is total duration of lying and sitting, as \% of 24 hours.

${ }^{4}$ Note that data on motility, bouts and self-reported physical activity were not available for able-bodied controls.

${ }^{5}$ Mean difference between all participants with CP and able-bodied persons.

${ }^{6}$ Difference in characteristics between all persons with $\mathrm{CP}$ and able-bodied persons was tested. Difference in physical activity and sedentary time was analysed with regression analyses correcting for age and gender.

${ }^{7}$ Corrected for age and gender, no significant differences were found in physical behaviour between participants with GMFCS level I and II ( $p>0.05$ ). Differences with the subgroup GMFCS level III were not assessed because sample size was limited.

${ }^{8}$ Corrected for age and gender, participants with bilateral CP had significantly higher number of sitting bouts $0-10$ sec ( $\left.p=0.04\right)$ and $10-60$ sec ( $\left.p=0.02\right)$ compared to unilateral CP. No other significant differences were found in physical behaviour between participants with bilateral and unilateral CP $(p>0.05)$.

*indicates significant difference $\mathrm{p}<0.05$.

GMFCS $=$ Gross Motor Functioning Classification System

PASIPD = Physical Activity Scale for Individuals with Physical Disabilities.

$\mathrm{Cl}=$ confidence interval.

Mean dif. $=$ mean difference

13-item, 7-day recall questionnaire developed for people with a physical disability. The scale consists of questions regarding leisure time, and household-related and workrelated physical activity. The total PASIPD score was calculated by multiplying the average hours per day for each item by a given metabolic equivalent (MET) value associated with the intensity of the activity. Because the PASIPD was developed for persons with physical disabilities, there are no reference data for able-bodied persons. 


\section{Statistical analysis}

An independent t-test was used to test for differences in age and a Chi-Square test to test for difference in gender between the total group of participants with $\mathrm{CP}$ and able-bodied persons. Regression analyses, correcting for age and gender, were used to assess differences in physical activity and sedentary time between participants with $\mathrm{CP}$ and able-bodied persons. Regression analyses correcting for age and gender were used to test for differences in physical behaviour between subgroups on basis of GMFCS level and CP distribution. Statistical analyses were performed using SPSS 20 (SPSS Inc, Chicago, IL). The significance level was set at $\mathrm{p}<0.05$.

\section{Results}

In total, 48 ambulatory adolescents and young adults with CP completed the physical behaviour measurements. Due to technological challenges with the activity monitor, data were not available for the intended three days for all participants. Measurement duration was 72 hours for $37 \%, 48$ hours for $51 \%$ and 24 hours for $12 \%$ of participants.

Characteristics of participants with $\mathrm{CP}$ and able-bodied persons are described in Table 1. No significant differences were found in age $(\mathrm{p}=0.1)$ and gender $(\mathrm{p}=0.5)$ between these groups. Furthermore, Table 1 shows data on physical activity, sedentary time and self-reported physical activity, and the comparison with able-bodied persons. Compared to able-bodied persons, persons with $\mathrm{CP}$ were significantly less physically active $(\mathrm{p}<0.01)$ and spent more time sedentary $(\mathrm{p}<0.01)$. On average, persons with CP participated 48 minutes per 24 hours less in physical activities compared to able-bodied controls (123 vs. 171 minutes/ $24 \mathrm{~h})$. Sedentary time was 80 minutes per 24 hours more in the group with CP compared to able-bodied controls (1147 vs. 1077 minutes/24 h). Self-reported physical activity level in participants with CP was on average 13.0 (8.6) MET-hr/day.

Between participants with GMFCS levels I and II, no significant differences were found in physical activity, sedentary behaviour, and self-reported physical activity level. Since the sample size of the subgroup with GMFCS level III was limited to four persons, statistics were not performed for this subgroup. When comparing unilateral and bilateral participants, only the number of sitting bouts $0-10 \sec (\mathrm{p}=0.04)$ and $10-60 \mathrm{sec}(\mathrm{p}=0.02)$ were significantly higher for participants with bilateral $\mathrm{CP}$.

\section{Discussion}

This was the first study to assess both physical activity and sedentary behaviour in a sample of ambulatory persons with spastic CP after childhood. Persons with CP participated 48 minutes less in physical activities and spent 80 minutes more sedentary per 24 hours, compared to able-bodied controls. A comparison between the present data and guidelines for healthy physical behaviour is difficult. The latter are primarily based on self-report using questionnaires to estimate overall physical behaviour, whereas our data are objective and based on continuous registrations [17]. Future studies defining guidelines based on objectively measured data are necessary.

Consistent with previously published studies, physical behaviour did not differ between participants with GMFCS levels I and II $[8,18,19]$. However, studies that included GMFCS level III and IV have shown significant associations between GMFCS level and physical activity $[8,20,21]$. Although we did not test for significance, physical activities seemed to be lower in persons with GMFCS level III (5.1\%) compared to GMFCS levels I and II (8.9\%), and sedentary times were higher as well $(87.4 \%$ vs. $78.8 \%)$. Therefore, the subgroup of GMFCS III seems to have even less favourable physical behaviour. Since this subgroup was only small, further research is necessary.

Compared to persons with unilateral CP, persons with bilateral CP had significantly more short sitting bouts of 0-10 seconds and 10-60 seconds. Previous studies suggest that these short sitting bouts are favourable behaviour in terms of reducing cardiovascular risk because they break up sedentary time [22]. If these short sitting bouts break up sedentary time, this would also lead to less sittings bouts of more than 30 minutes [23]. However, the numbers of these long sitting bouts were comparable in both subgroups. Since the number of short sitting bouts was the only difference between persons with unilateral $\mathrm{CP}$ and bilateral $\mathrm{CP}$, we can conclude that these subgroups are comparable with regard to movement behaviour and health problems.

Although physical behaviour was found to be less favourable in adolescents and young adults with CP, physical strain may be comparable or higher compared to able-bodied persons. Previously, it had been reported that physical strain during walking is higher in persons with $\mathrm{CP}$ compared to reference groups [19], and that the physical strain of walking is inversely related to the total time of daily walking $[19,24]$. Because of higher physical strain, persons with $\mathrm{CP}$ may be less active in daily life to conserve energy or prevent fatigue [19,24]. Unfortunately, physical strain during the objective measurement of physical activities was not assessed in the present study. It is unknown how this higher strain in persons with $\mathrm{CP}$ relates to the risk of cardiovascular disease and other chronic diseases related to physical behaviour.

Self-reported physical activity was relatively high in the present sample of ambulatory adolescents and young adults with CP (13.0 MET-hour/day, SD = 8.6), as compared to previously published self-reported physical activity in ambulatory persons with $\mathrm{CP}$ and meningomyelocele 
(11.3 MET-hour/day $(\mathrm{SD}=8.6))$ [17]. However, objectively measured physical activity was also reported to be lower in those groups: $8.1 \%$ in adults with bilateral CP and $7.8 \%$ in ambulatory persons with meningomyelocele, compared to $8.6 \%$ in the current sample [25].

\section{Limitations}

Although a large number of persons with varying GMFCS levels were invited to participate, our sample included only four persons with GMFCS level III. Further research is required in persons with lower functioning GMFCS levels, including GMFCS level III and IV and wheelchairbound persons. Wearing the activity monitor may have influenced activities in daily life, despite participants' reports that they were able to perform their regular activities. Although all measurements took place on weekdays and no significant differences were found between days, measurement duration in participants with $\mathrm{CP}$ was one to three days while measurement duration in able-bodied persons was two days. Furthermore, comparisons between persons with $\mathrm{CP}$ and able-bodied persons have to be interpreted with some caution since in able-bodied persons a previous version of the activity monitor and software was used. However, the underlying technique and analysis procedures were comparable between versions and therefore no differences between systems versions are expected.

Our study may overestimate physical activity because of selection bias; persons with $\mathrm{CP}$ interested in physical activity and sports may have been more likely to participate in the study. Despite of that, this group was less physical active and had more sedentary time compared to reference.

\section{Conclusions}

Objective measurements show that ambulatory adolescents and young adults with $\mathrm{CP}$ are less physically active and spend more time sedentary compared to able-bodied persons, suggesting that this group may be at increased risk for health problems related to less favourable physical behaviour.

\section{Consent}

Consent for publication has been obtained from the person on Figure 1.

\footnotetext{
Abbreviations

CP: Cerebral palsy; GMFCS: Gross Motor Functioning Classification System; MET: Metabolic equivalent; PASIPD: Physical Activity Scale for Individuals with Physical Disabilities; g: Gravitational forces.

Competing interests

The authors declare that they have no competing interests.

\section{Authors' contributions}

$\mathrm{CN}$ contributed to design, data analysis, interpretation of data and drafting the manuscript, JS to design, acquisition, interpretation of data and reviewing the manuscript, HS and MR to design, interpretation of data and
}

reviewing the manuscript, and RB to design, data analysis, interpretation of data and drafting the manuscript. All authors read and approved the final manuscript.

\section{Acknowledgements}

This project was funded by ZonMW (nr. 60-61300-98-003) and Phelps Stichting voor Spastici (nr. 2008039).

The following members of the Learn2Move Research Group contributed to this study: Department of Rehabilitation Medicine, Erasmus MC, University Medical Centre, Rotterdam (J. van Meeteren); Rijndam Rehabilitation Centre, Rotterdam (W. van der Slot); Sophia Rehabilitation, The Hague (F. van Markus); Department of Rehabilitation, VUmc, Amsterdam (A. Dallmeijer); Rehabilitation Centre De Hoogstraat, Utrecht (A. Wensink); and the Association of Physically Disabled Persons and their Parents (BOSK).

Received: 11 November 2013 Accepted: 17 March 2014

Published: 3 April 2014

\section{References}

1. Caspersen CJ, Powell KE, Christenson GM: Physical activity, exercise, and physical fitness: definitions and distinctions for health-related research. Public Health Rep 1985, 100(2):126-131.

2. Warburton DE, Nicol CW, Bredin SS: Health benefits of physical activity: the evidence. Cmaj 2006, 174(6):801-809.

3. Thorp AA, Owen N, Neuhaus M, Dunstan DW: Sedentary behaviors and subsequent health outcomes in adults a systematic review of longitudinal studies, 1996-2011. Am J Prev Med 2011, 41(2):207-215.

4. Hamilton MT, Healy GN, Dunstan DW, Zderic TW, Owen N: Too little exercise and too much sitting: Inactivity physiology and the need for new recommendations on sedentary behavior. Curr Cardiovasc Risk Rep 2008, 2(4):292-298.

5. Bussmann JB, van den Berg-Emons RJ: To total amount of activity..... and beyond: perspectives on measuring physical behavior. Front Psychol 2013, 4:463.

6. Peterson MD, Gordon PM, Hurvitz EA: Chronic disease risk among adults with cerebral palsy: the role of premature sarcopoenia, obesity and sedentary behaviour. Obes Rev 2013, 14(2):171-182.

7. Carlon SL, Taylor NF, Dodd KJ, Shields N: Differences in habitual physical activity levels of young people with cerebral palsy and their typically developing peers: a systematic review. Disabil Rehabil 2013, 35(8):647-655.

8. Nieuwenhuijsen C, van der Slot WM, Beelen A, Arendzen JH, Roebroeck ME, Stam HJ, van den Berg-Emons RJ, Transition Research Group South West N: Inactive lifestyle in adults with bilateral spastic cerebral palsy. J Rehabil Med 2009, 41(5):375-381.

9. Nieuwenhuijsen C, van der Slot WM, Dallmeijer AJ, Janssens PJ, Stam HJ, Roebroeck ME, van den Berg-Emons HJ, Transition Research Group South West N: Physical fitness, everyday physical activity, and fatigue in ambulatory adults with bilateral spastic cerebral palsy. Scand J Med Sci Sports 2011, 21(4):535-542.

10. Telama R, Yang X, Viikari J, Valimaki I, Wanne O, Raitakari O: Physical activity from childhood to adulthood: a 21-year tracking study. Am J Prev Med 2005, 28(3):267-273.

11. Roebroeck ME, Jahnsen R, Carona C, Kent RM, Chamberlain MA: Adult outcomes and lifespan issues for people with childhood-onset physical disability. Dev Med Child Neurol 2009, 51(8):670-678.

12. Slaman J, Roebroeck ME, van Meeteren J, van der Slot WM, Reinders-Messelink HA, Lindeman E, Stam HJ, van den Berg-Emons RJ: Learn 2 Move 16-24: effectiveness of an intervention to stimulate physical activity and improve physical fitness of adolescents and young adults with spastic cerebral palsy; a randomized controlled trial. BMC Pediatr 2010, 10:79.

13. Bussmann J, Martens WL, Tulen JH, Schasfoort FC, van den Berg-Emons HJ Stam HJ: Measuring daily behavior using ambulatory accelerometry: the Activity Monitor. Behav Res Methods Instrum Comput 2001, 33:349-356.

14. Postma K, van den Berg-Emons HJ, Bussmann JB, Sluis TA, Bergen MP, Stam HJ: Validity of the detection of wheelchair propulsion as measured with an Activity Monitor in patients with spinal cord injury. Spinal Cord 2005, 43:550-557.

15. White DK, Wagenaar RC, Del Olmo ME, Ellis TD: Test-retest reliability of 24 hours of activity monitoring in individuals with Parkinson's disease in home and community. Neurorehabil Neural Repair 2007, 21(4):327-340. 
16. Washburn R, Zhu W, McAuley E, Frogley M, Figoni SF: The physical activity scale for individuals with physical disabilities: development and evaluation. Arch Phys Med Rehabil 2002, 83(2):193-200.

17. van den Berg-Emons RJ, L'Ortye AA, Buffart LM, Nieuwenhuijsen C, Nooijen CF, Bergen MP, Stam HJ, Bussmann JB: Validation of the Physical Activity Scale for individuals with physical disabilities. Arch Phys Med Rehabil 2011, 92(6):923-928.

18. Berger W: Characteristics of locomotor control in children with cerebral palsy. Neurosci Biobehav Rev 1998, 22(4):579-582.

19. Maltais DB, Pierrynowski MR, Galea VA, Bar-Or O: Physical activity level is associated with the $\mathrm{O} 2$ cost of walking in cerebral palsy. Med Sci Sports Exerc 2005, 37(3):347-353.

20. Bell KL, Davies PS: Energy expenditure and physical activity of ambulatory children with cerebral palsy and of typically developing children. Am J Clin Nutr 2010, 92(2):313-319.

21. Heller T, Ying Gs GS, Rimmer JH, Marks BA: Determinants of exercise in adults with cerebral palsy. Public Health Nurs 2002, 19(3):223-231.

22. Dunstan DW, Thorp AA, Healy GN: Prolonged sitting: is it a distinct coronary heart disease risk factor? Curr Opin Cardiol 2011, 26(5):412-419.

23. Manns PJ, Dunstan DW, Owen N, Healy GN: Addressing the nonexercise part of the activity continuum: a more realistic and achievable approach to activity programming for adults with mobility disability? Phys Ther 2012, 92(4):614-625.

24. Slaman J, Bussmann J, van der Slot WM, Stam HJ, Roebroeck ME, van den Berg-Emons RJ, Transition, Lifespan Research Group South West N: Physical strain of walking relates to activity level in adults with cerebral palsy. Arch Phys Med Rehabil 2013, 94(5):896-901.

25. van den Berg-Emons RJ, Bussmann JB, Stam HJ: Accelerometry-based activity spectrum in persons with chronic physical conditions. Arch Phys Med Rehabil 2010, 91(12):1856-1861.

doi:10.1186/1743-0003-11-49

Cite this article as: Nooijen et al:: Inactive and sedentary lifestyles amongst ambulatory adolescents and young adults with cerebral palsy. Journal of NeuroEngineering and Rehabilitation 2014 11:49.

\section{Submit your next manuscript to BioMed Central and take full advantage of:}

- Convenient online submission

- Thorough peer review

- No space constraints or color figure charges

- Immediate publication on acceptance

- Inclusion in PubMed, CAS, Scopus and Google Scholar

- Research which is freely available for redistribution 